\title{
Morphological Appearance of Condylar Head in Mixed Denti- tion Period (Evaluated from Panoramic Radiograph)
}

\author{
Lydia Tanu ${ }^{1}$, Hendra Polii*, Dian Lesmana ** \\ 1 Faculty of Dentistry, Maranatha Christian University, Bandung, Indonesia 40164; \\ 2095012@dent.maranatha.edu \\ * Department of Dental Radiology, Faculty of Dentistry, Maranatha Christian University, Bandung, Indonesia, \\ 40164; hendra.polii@dent.maranatha.edu \\ ** Department of Medical Physiology, Faculty of Dentistry, Maranatha Christian University, Bandung, Indo- \\ nesia 40164; dian.lesmana@dent.maranatha.edu
}

\begin{abstract}
Introduction: During mixed dentition period, the growth and development process of dentocraniofacial complex occurs, with temporomandibular joint as one of its centers of growth. The condition of temporomandibular joint can be seen from its condylar head shape; therefore, it is essential to understand the normal morphology of condylar head during mixed dentition period. Objective: this research aims to view the general morphology of condylar head during mixed dentition period. Method: Samples of panoramic radiographs were collected from Maranatha Dental Hospital, Bandung, Indonesia. It consists of 70 male and 70 female subjects, divided into three groups according to their phase of mixed dentition period. Shape of subjects' condylar heads was determined by analyzing and comparing the tracing results of condyle in panoramic radiograph. Result: Study showed in first transitional period of mixed dentition, condylar head shape is dominated by round, as growth and development go on, the domination of condylar head shape is changed into convex on second transitional period. Conclusion: Mostly condylar head shape morphology during mixed dentition period is round-headed in first transitional and inter-transitional period, and convex-headed in second transitional period.
\end{abstract}

Keywords: mixed dentition period; temporomandibular joint; mandibular condyle; panoramic radiograph

\section{Introduction}

Mixed dentition is a transition stage between deciduous and permanent dentition. This period begins when emergence of first mandibular permanent molars occurs and the end of period is marked by the exfoliation of the last deciduous teeth in the oral cavity [1]. This period is crucial, every developmental change that happens in mixed dentition period will determine occlusal relationship in permanent dentition, that lasts a lifetime [2]. In mixed dentition period, a lot of dentocraniofacial anomalies can be seen, whether its self-correcting as the growth and development goes on, or possibly permanent dentocraniofacial anomalies that needed to be treated right away to prevent further abnormalities [3].

During mixed dentition period, both emergence and exfoliation of teeth occur simultaneously in oral cavity, causing significant changes in teeth alignment, thus might affect occlusal relation. Those changes might be normal and self-correcting, or abnormal that might lead to permanent malocclusion or other craniofacial development disturbance [4]. Changes of occlusion may also affect mastication because occlusal features will directly affect the electrical signal activity of masticatory muscles [5]. Occlusal relationship changes in mixed dentition period can alter diet preferences and triggering oral bad habits that might disrupt the balance of masticatory function. Normal masticatory function must be maintained to prevent craniofacial deformities in the future [6,7]. 
Temporomandibular joint (TMJ) is a synovial joint, consists of three main bony components: condylar process, articular eminence, and glenoid fossa. TMJ receives complex force on jaw movements during mastication, which is concentrated on the condylar process [8]. Condylar process is known as one of mandibular growth centers that has a significant role in mandibular growth and development. Main factors affecting mandibular growth are condylar growth and masticatory muscles activities [6].

Various shapes and sizes of condylar head had been obtained in several previous studies. In general, shapes of condylar head are classified as convex, angled, round, and flattened [9]. Assessment of condylar process shape can be used as an indicator of Temporomandibular Joint Disorders (TMDs). Therefore, dental clinician needs to comprehend the difference between normal and abnormal morphology of condylar process to help diagnosing and treating signs of TMDs as early as possible [10].

Panoramic radiograph is one of imaging modality that has been used widely in dentistry. Panoramic radiograph or as known as Orthopantomogram (OPG), presents single tomographic image of facial structures that includes maxillary and mandibular arch and adjacent anatomical structures such as temporomandibular joint [12]. Panoramic imaging provides essential data that can be useful for early diagnosis of TMDs as it presents a two-dimension anatomical image of condylar process and glenoid fossa that acts as important parts in temporomandibular joint [13].

The objection of this study is to understand the general morphology of condylar head during mixed dentition period, thus can be referenced for early diagnosis of temporomandibular disorders.

\section{Materials and Methods}

Machines and software used in this study include: Morita Veraviewepocs 3DR100, Samsung Galaxy Note, Morita i-Dixel, Galaxy Note Photoviewer.

Method used in this study is analytic descriptive with retrospective design and qualitative approach. Population included are all patient in mixed dentition period whom have received or currently receiving any treatment at integrated dental clinic, general dental clinic, or pediatric dental clinic in Maranatha Dental Hospital, Bandung, Indonesia. Samples included in this study are all patient in population that meets the exclusion and inclusion criteria and have done panoramic imaging in Maranatha Dental Hospital, Bandung, Indonesia. Sampling method used in this study is simple random sampling.

\section{Results}

Data collected from Radiology Center of Maranatha Dental Hospital, Bandung, Indonesia (2013-2019), consists of 628 panoramic radiographs of patients with 6-13 years old age range that fulfills the inclusion and exclusion criteria, there are 371 data of male patients and 257 data of female patients. Samples are chosen randomly by simple random sampling method, resulting in 70 data of male subjects and 70 female subjects included in this study.

Subjects are divided into three groups based on their mixed dentition phase that had been identified from patients' age on medical record and dental development phase that can be seen from patients' panoramic radiograph. Subject grouping based on genders and mixed dentition phase can be seen at Table 1 below. 
Table 1. Subjects grouping based on gender and mixed dentition phase

\begin{tabular}{lccc}
\hline \multicolumn{1}{c}{ Mixed Dentition Phase } & $\begin{array}{c}\text { Male } \\
\text { Subjects }\end{array}$ & $\begin{array}{c}\text { Female Sub- } \\
\text { jects }\end{array}$ & Total \\
\hline First transitional period & 33 & 32 & 65 \\
Inter-transitional period & 27 & 25 & 52 \\
Second transitional period & 11 & 12 & 23 \\
\hline Total & 70 & 70 & 140 \\
\hline
\end{tabular}

Distribution of all 140 subjects' condylar head shape can be seen on Table 2 below.

Table 2. Distribution of subjects' condylar head shape

\begin{tabular}{clcc}
\hline Shape of Condylar Head & \multicolumn{1}{c}{ Side } & Total \\
\hline \multirow{2}{*}{ Convex } & Right condyle & 57 & 117 \\
& Left condyle & 60 & 115 \\
Round & Right condyle & 63 & \multirow{2}{*}{4} \\
\multirow{2}{*}{ Flat } & Left condyle & 52 & \\
\multirow{2}{*}{ Angled } & Right condyle & 19 & 4 \\
\hline
\end{tabular}

Based on data obtained, Diagram 1 below shows overall distribution of subject's condylar head shape during particular phase of mixed dentition period.

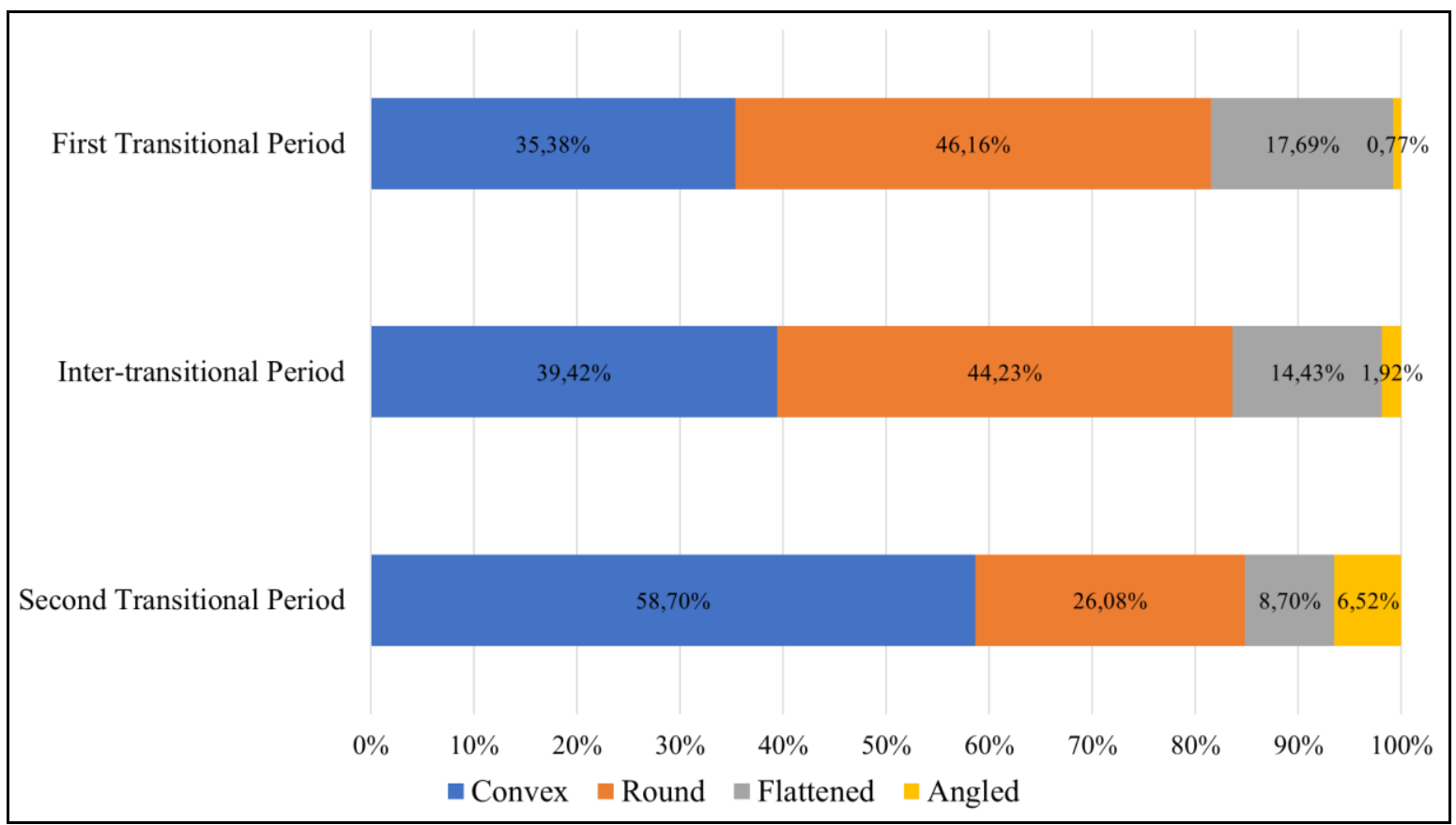

Figure 1. Percentage of condylar head shape according to certain phase of mixed dentition period

Result of this study concludes that there is a significant difference in dominant condylar head shape in every phase of mixed dentition period. Result has shown that number of convex and angled shaped condylar head are increasing within the development of dentition, in contrary the number of round and flat shaped condylar head are decreasing within the development of dentition. Figure 2 presents subjects' percentage of condylar head shape within the development of mixed dentition period. 


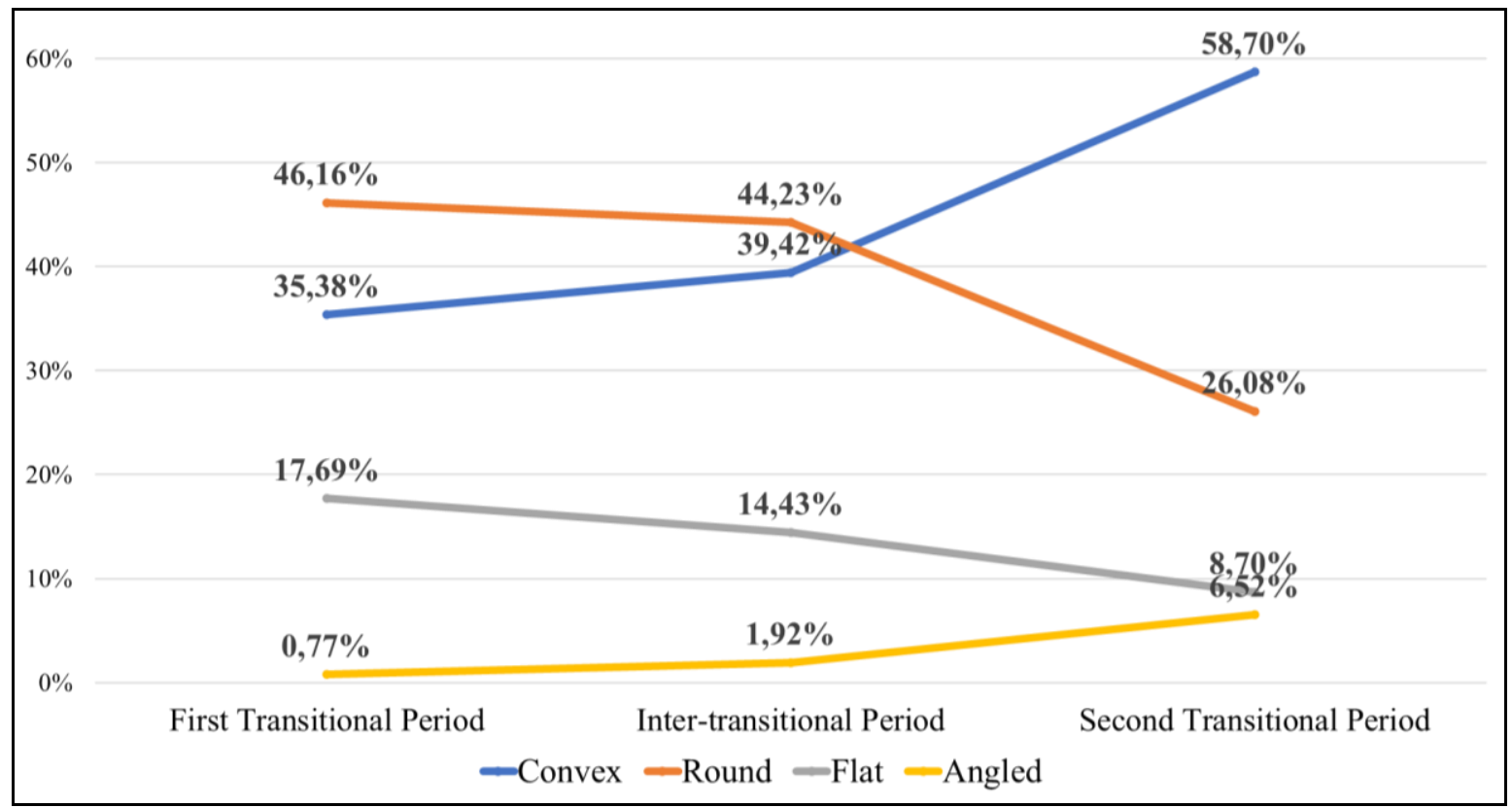

Figure 2. Percentage of subjects' condylar head shape according to mixed dentition phase

\section{Discussion}

All 140 subjects included in this study divided into three main groups based on their phase of mixed dentition period. Subjects that meet inclusion and exclusion criteria mostly are five to seven years old or in first transitional period, thus subjects in first transitional period had more probability to be selected as samples.

Condylar head shape varies in each individual, both normally or pathologically. Classification of condylar head shape used in this study, according to Yale, is divided into four main shapes: convex, round, flat, and angled [9]. Theoretically and based on previous research, normal condylar morphology in most adults is convex-shaped condyle [14]. Round-shaped condylar head is also considered normal, but round-shaped condyle found to be less prevalent than convex in adults [15]. However flat and angled are considered as pathological form of condylar head shape that happened as a result of particular condition that caused pathological wear, such as bad oral habits or growth and developmental disturbance [14].

Mandibular condyle development starts at early stages of life and continuously remodel as an adaptive response to anatomical and functional changes that happened during growth and development. Condylar cartilage plays a considerable role in mandibular development and determine final morphology and composition of mandibular condyle [16]. In infants, condylar cartilage acts as growth cartilage that works similarly with cartilages found at long bone plates so that a vast growth potential might be related to this. Round condylar head shape is the most common condylar head shape found in infants, as growth and development occur, elongation and condylar ossification toward articular surface will happen [17].

In first transitional period of mixed dentition, the morphology of condylar head was dominated by round-shaped condyle. In inter-transitional period of mixed dentition, the morphology of condylar head was still dominated by round shape, but the difference of percentage between round and convex-shaped condyle is decreasing compared to previous phase. In second transitional period of mixed dentition, the most dominant morphological shape of condylar head is convex. This result is in line with previous theory stating that the most common condylar head shape found in children is round, as development occurs condyle will elongate, resulting in the change of morphology into convex-shaped condyle, the most common condylar head shape found in adults [15]. 
As age increasing and growth and development occurs in children, lots of changes will happen in temporomandibular joint. At the age of five to six, a child began to enter mixed dentition in first transitional period. In this age, the decreasing of condylar cartilage thickness and amount of vascularization in articular surface of condyle also start to happen. The reduction of condylar cartilage thickness will affect the shape of condylar head in a certain amount of time [18]. Figure 1 shown that in first transitional period the most to least common condylar head shape found is round (46.16\%), convex $(33.38 \%)$, flat $(17.69 \%)$, and angled $(0.77 \%)$. Previous theory stating condylar head shape in children are mostly round-headed and coated with thick cartilage is in line with this research result [17].

In inter-transitional period that happened at the age of eight to ten, further development of occlusion is occurring and can be seen by the emergence of canine bulge and fully erupted permanent incisives and permanent first molars [19]. In inter-transitional period, as shown at Figure 1, round-shaped condylar head is still dominating (44.32\%), but the percentage difference between round and convex-shaped condylar head decreased by $5,97 \%$ in comparison to previous phase (first transitional period). Most subjects in inter-transitional period with convex condylar head shape had lower position of canine bulge compared to subjects with round condylar head shape, indicating that subjects with convex condylar head shape most likely are at a more mature developmental phase than subjects with round condylar head shape. In inter-transitional period, transition of condylar head shape from round to convex is taking place.

Second transitional period is the end of transition phase from mixed to permanent dentition. Establishment of occlusion happened in this phase, at the age of ten to twelve. Second transitional period clinically can be seen from the eruption of permanent second molars and premolars. Increased height of dentofacial bone and the change of hypertrophic and proliferative zone of condyle are also taking place in this phase [19]. Elongation of condylar head as a result of calcification and ossification will also be more visible in this phase. Condylar head morphology will more likely lead to convex-shaped, the most common normal condyle shape found in adults [15]. As seen in Figure 1, percentage of convex-shaped condylar head in second transitional period increases significantly $(58.70 \%)$, surpassing round-shaped condylar head $(26.08 \%)$ that most commonly found in first and inter-transitional period. This indicates that at the end of mixed dentition period, most normal individuals without occlusion abnormalities, bad habits, and developmental disturbances had convex-shaped condylar head.

Figure 2 summarizes that round-shaped, the most common condylar head shape in infants are also the most commonly found condylar head shape in first transitional phase of mixed dentition period. As growth and development occurs, the number of round-headed condyle is gradually decreasing within next phases. In contrary, the number of convex-headed condyle as most commonly found in normal adults and also second transitional period of mixed dentition in this research is gradually increasing as growth and development occur. Round and convex shaped condyle are considered as normal morphologies of temporomandibular joint. In contrast, flat and angled shaped condyle are considered as abnormal morphologies of temporomandibular joint as a result of pathological conditions.

\section{Conclusions}

Morphological appearance of condylar head in normal individual at first transitional period of mixed dentition is round-shaped $(46.16 \%)$, at inter-transitional period of mixed dentition is round-shaped $(44.23 \%)$, and at second transitional period of mixed dentition is convex $(58.70 \%)$. 


\section{References}

1. McDonald RE, Avery DR, Dean JA, McDonald and Avery Dentistry for Child and Adolescence. Ninth edition. Maryland Heights: Mosby/Elsevier, 2011. p625-84.

2. Yu X, Zhang H, Sun L, Pan J, Liu Y, Chen L. Prevalence of malocclusion and occlusal traits in the early mixed dentition in Shanghai, China. PeerJ. 2019;7(1)23-31.

3. Ueda HM, Miyamoto K, Saifuddin MD, Ishizuka Y, Tanne K. Masticatory muscle activity in children and adults with different facial types. Am J Orthod Dentofac Orthop. 2000;118(1):63-8.

4. Bell RA, Sonis A. Space supervision and guidance of eruption in management of lower transitional crowding: A non-extraction approach. Semin Orthod. 2014;20(1):16-35.

5. Trovato F, Orlando B, Bosco M. Occlusal features and masticatory muscles activity. A review of electromyographic studies. Stomatologija. 2009;11(1):26-31.

6. Gomes FEF, Moraes RB, Luz JGDC. Effects of temporal muscle detachment and coronoidotomy on facial growth in young rats. Braz Oral Res. 2012;26(4):348-54.

7. Castelo PM, Pereira LJ, Bonjardim LR, Gavião MBD. Changes in bite force, masticatory muscle thickness, and facial morphology between primary and mixed dentition in preschool children with normal occlusion. Ann Anat. 2010;192(1):23-6.

8. Miyazaki M, Yonemitsu I, Takei M, Kure-Hattori I, Ono T. The imbalance of masticatory muscle activity affects the asymmetric growth of condylar cartilage and subchondral bone in rats. Arch Oral Biol. 2016;63(1):22-31.

9. Praveen BN SH. Morphological and radiological variations of mandibular condyles in health and diseases: a systematic review. Dentistry. 2013;3(1):1-5.

10. Karlo CA, Stolzmann P, Habernig S, Müller L, Saurenmann T, Kellenberger CJ. Size, shape and age-related changes of the mandibular condyle during childhood. Eur Radiol. 2010;20(10):2512-7.

11. Okeson JP. Temporomandibular disorders in children and adolescents. Gen Dent. 2018;66(6):51-5.

12. White SC, Pharoah MJ. Oral Radiology Principles and Interpretation. Fifth edition. Mosby. 2004. p43-67

13. Soni V, Buch B. An assessment of the accuracy of a panoramic radiograph as compared with cone-beam tomography in TMJ imaging. South African Dent J. 2017;75(5).

14. Ribiero EC, Sanches ML, Alonso LG, Smith LR. Shape and symmetry of human condyle and mandibular fossa. Int J Odontostomatol. 2015;9(1):65-72.

15. Kartikeyan B, Sadaksharam J, Yesupogu HB. Analysis of morphological variation of condyle by cone-beam computed tomography. J Ind Academy Oral Med Rad. 2016;28(1):66-69

16. Sahithi D, Reddy S, Teja DVD, Koneru J, Nagavenkata K, Praveen S, Sruthi R. Reveal the concealed : morphological variations of coronoid process , condyle and sigmoid notch in personal identification. Egypt J Forensic Sci. 2015;6(2):108-113

17. Copray JC, Dibbets JM, Kantomaa T. The role of condylar cartilage in the development of the temporomandibular joint. Angle Orthod. 2008;58(4):369-80

18. Thilander B, Carlsson GE, Ingervall B. Postnatal development of the human temporomandibular joint: a histological study. Acta Odontol Scand. 2007;34(2):117-26.

19. Singh G. Textbook of Orthodontics. Second edition. New Delhi: Jaypee; 2007. p7-53

20. Capote TS de O. Panoramic radiography: diagnosis of relevant structures that might compromise oral and general health of the patient. IntechOpen; 2015;12(2)

21. Agarwal V, Mehrotra N, Vijay V. Gingival biotype assessment: variations in gingival thickness with regard to age, gender, and arch location. Indian J Dent Sci. 2017; 9(1):12-5.

22. Bender ME, Lipin RB, Goudy SL. Development of the pediatric temporomandibular joint. Oral Maxillofac Surg Clin North Am. 2018;30(1):1-9.

23. Cameron AC, Widmer RP. Handbook of Pediatric Dentistry. Fourth edition. Canberra: Mosby; 2013. p341-68.

24. Csadó K, Márton K, Kivovics P. Anatomical changes in the structure of the temporomandibular joint caused by complete edentulousness. Gerodontology. 2012;29(2):111-6.

25. Glick M. Burket's Oral Medicine. Twelfth edition. New Delhi: Jaypee Brothers; 2015. p263-309

26. Gunson A. Condylar resorption: a review. J Dentomaxillofacial Sci. 2010;43(1):17-25.

27. Hedge V A review of the disorder of the temporomandibular joint. J Ind Pros Surg. 2005;5(2):56-61

28. Hudson AP, Harris AM, Mohamed N. The mixed dentition pantomogram: a valuable dental development assessment tool for the dentist. SADJ. 2009;64(10):480-3.

29. Jannuci J, Howerton L. Dental Radiography: Principles and Techniques. Fifth edition. Missouri: Elsevier; 2017. p68-90

30. Miloro M. Peterson's Principles of Oral and Maxillofacial Surgery. Second edition. London: BC Decker; 2004 . p933-49.

31. Nanci, A. Ten Cate's Oral Histology: Development, Structure, and Function. Seventh edition. St.Louis: Elsevier; 2008. p358-77

32. Neto JV, Estrela C, Bueno MR, Guedes OA, Porto OCL, Pecora JD. Mandibular condyle dimensional changes in subjects 3 to 20 years of age using cone-beam computed tomography: a preliminary study. Dent Press J Orthod. 2010;15(5):172-181

33. Okeson JP. Management of Temporomandibular Disorder. Eighth edition. St.Louis: Elsevier; 2008. p2-21.

34. Sa SC, Melo SL, Melo DP, Freitas DQ, Campos PS. Relationship between articular eminence and condyle : a cbct study. Braz Oral Res. 2017;31(1):1-8. 
35. Shetty US, Burde KN, Naikmasur VG, Sattur AP. Assessment of condylar changes in patients with temporomandibular joint pain using digital volumetric tomography. Radiol Res Pract. 2014;4(1):1-8.

36. Smartt JM, Low DW, Bartlett SP. The pediatric mandible: a primer on growth and development. Plast Reconstr Surg. 2005;116(1):258.

37. Snedecor GW, Cochran WG. Statistical Methods. Sixth edition. Iowa: Iowa State University Press; 1968. p69-90

38. Sonal V, Sandeep P, Kapil G, Christine R. Evaluation of condylar morphology using panoramic radiography. J Adv Clin Res Insights. 2016;3(1):5-8.

39. Whaites E. Essentials of Dental Radiography and Radiology. Third edition. London: Elsevier; 2003. p161-77

40. Withers S, Heyde M. Panoramic radiographs: technique and anatomy review. J Dent Care. 2018;62(1):5-15. 